\title{
Las realidades mineras impulsan el comercio internacional. El caso de Colombia (2008-2017)
}

Mining realities boost the international commerce.

The case of Colombia (2008-2017)

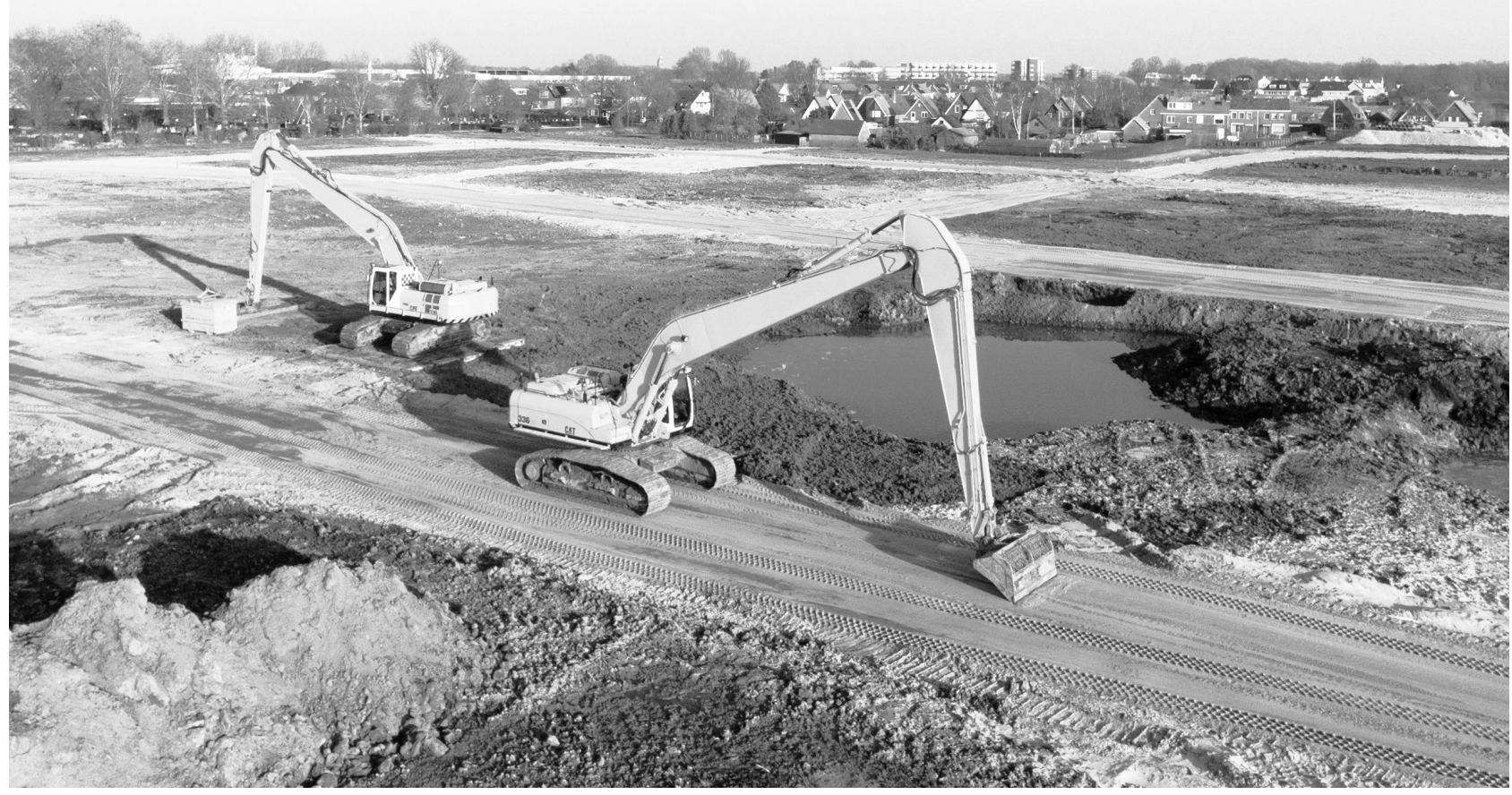




\title{
Las realidades mineras impulsan el comercio internacional. El caso de Colombia (2008-2017) ${ }^{1}$ Mining realities boost the international commerce. The case of Colombia (2008-2017)
}

\section{Bernardo Congote Ochoa ${ }^{2}$}

Artículo recibido en julio 29 de 2019; artículo aceptado en octubre 15 de 2019

Este artículo puede compartirse bajo la Licencia Creative Commons Atribución-NoComercial-Compartirlgual 4.0 Internacional y se referencia usando el siguiente formato: Congote, B. (2020). Las realidades mineras impulsan el comercio internacional. El caso de Colombia (2008-2017). I+D Revista de Investigaciones, 15 (1), 85-93. DOI: https://doi.org/10.33304/revinv.v15n1-2020009

\section{Resumen}

El artículo intenta probar la hipótesis de que el sector minero colombiano ha impulsado la economía internacional hasta el punto de que ningún otro sector estaría en capacidad de emularla, al menos en el corto plazo. Las discusiones que califican la minería como una especie de "enfermedad nacional" suelen carecer de datos. En consecuencia, en este artículo se presenta y se analiza una serie estadística sobre las exportaciones e importaciones colombianas, según sectores CIIU, en el lapso 2008-2017; asimismo, se realiza un análisis cruzado de ambas series, buscando precisar el impacto de la minería sobre la dinámica del comercio internacional colombiano; y finalmente se emiten algunas conclusiones y recomendaciones. La metodología es descriptiva-explicativa. Los resultados permiten probar la hipótesis e indicarían cómo el crecimiento intersectorial desigual es una realidad económica, lo que pone en duda, desde el enfoque minero, algunas de las críticas que rodean la dinámica del sector en Colombia.

Palabras clave: Comercio internacional, crecimiento desigual, datos mineros, fortalezas mineras, realidad minera.

\begin{abstract}
The article attempts to test the hypothesis that the Colombian mining sector has boosted the international economy, to the point that no other sector would be able to emulate it, at least in the short term. Discussions that describe mining as a kind of a "national disease" often lack data. Therefore, the article presents and analyzes a statistical series on Colombian exports and imports, according to ISIC sectors, during the 2008-2017 period; then, it presents a crossedanalysis of both series, seeking to specify the impact of mining on the dynamics of Colombian international trade; finally, it emits some conclusions and recommendations. The study follows a descriptive-explanatory methodology. The findings prove that the unequal intersectoral growth is an economic reality, and calls into question, from the mining approach, some of the criticisms surrounding the dynamics of this sector in Colombia.
\end{abstract}

Keywords: International trade, unequal growing, mining data, mining powers, mining realities.

\footnotetext{
'Artículo de investigación de tipo descriptivo explicativo, de enfoque mixto (cuantitativo y cualitativo), resultado de un proceso de investigación académica culminado, perteneciente al área ciencias administrativas y económicas, sub área de negocios internacionales, desarrollado en la Universidad Antonio Nariño (Bogotá, Colombia), en el lapso 2016-2019. Fecha de inicio: marzo de 2019. Fecha de terminación: julio de 2019.

${ }^{2}$ Magíster en Ciencia Política, Universidad de los Andes. Profesional en Economía, Universidad Nacional de Colombia. Investigador Júnior (Colciencias 2019). Miembro del Consejo Internacional de Federalismo y Libertad (Argentina). Docente-investigador del grupo SERVIPÚBLICOS (Colciencias B). Profesor asistente de tiempo completo, Universidad Antonio Nariño (Bogotá, Colombia). Dirección: calle 58.a n. ${ }^{\circ}$ 37-94, Bogotá (Colombia). PBX: 2213257. ORCID: https://orcid.org/0000-0003-3049-7815. Correo electrónico institucional: bernardo.congote@uan.edu.co
} 


\section{Introducción}

En Colombia, como posiblemente ocurre en otros países, la minería se considera más como una "enfermedad" que como un sector dinámico. Para contrastar este fenómeno, el autor intenta probar la hipótesis de que, observado el lapso 2008-2017, podría afirmarse que el sector minero colombiano poseería una dinámica económica internacional tal que, al menos en el corto plazo, ningún otro sector estaría en capacidad de emular.

Recientes campañas políticas en Colombia han oído de un candidato de izquierda, Gustavo Petro, proponer la sustitución de las exportaciones mineras a cambio de promover la exportación de aguacates (paltas). Por su parte, su contrincante, Iván Duque (elegido presidente por un partido minoritario de derecha), propuso que lo que se conoce como "economía naranja" resultaría un adecuado sustituto de la dinámica minera (Buitrago \& Duque, 2013; Ortiz, 2019).

Al analizar datos del período 2008-2017, el artículo ofrece algunas herramientas que podrían contribuir a probar su hipótesis al menos de forma preliminar ${ }^{3}$. Sobre todo, porque lo que se califica como "enfermedad minera" sugiere que algunos de los llamados demagógicamente como remedios resulten pésimas soluciones a un problema inexistente. No podría presentarse como problemático que el sector minero mostrara sus probadas fortalezas. Al contrario, convendría mirar hacia las condiciones de desarrollo de los demás sectores cuyos datos prueban que son ellas las que están causando graves patologías.

A manera de balance, se está en riesgo de adoptar como camino de solución el estancamiento relativo, que llevará a dar otro salto al vacío, diseñando e implementando políticas económicas inocuas.

\section{Marco teórico}

El marco teórico se fundamenta en algunas propuestas relacionadas con la inestabilidad estructural del sistema capitalista y, en paralelo, del aparato estatal (Engels \& Marx, 2004; Poulantzas, 1980). La pretensión de cierto "desarrollo equilibrado", anclada en concepciones deterministas newtonianas que hoy amenazan la obsolescencia, tendría acciones en las distorsiones que acompañan el debate sobre la influencia preponderante del sector minero en la dinámica económica colombiana. Esto, si se considera también que este escenario podría caracterizar la situación de otros países involucrados en la explotación de minerales en el planeta.

Convendría correlacionar el problema con algunas tesis

\footnotetext{
${ }^{3}$ Una investigación sobre una serie de datos más amplia busca ser el objetivo académico inmediato del autor de este artículo.
}

sobre la entropía y la mecánica cuántica (Prigogine, 1993; Prigogine \& Stengers, 1983), junto con enfoques sobre el pensamiento complejo y la circularidad y espiralidad del conocimiento (Morin, 1977, 1982, 1990, 1992). Por esta ruta, se busca darle soporte a la idea de que el desequilibrio es un elemento explicativo de la dinámica económica, como lo es del movimiento de las partículas en el universo (Hawking \& Mlodinow, 2010; Serway \& Jewet., 2002). Ello conduciría a abrirles paso a nuevos planos de discusión, como, por ejemplo, el impacto positivo del desarrollo desigual de la minería en Colombia. De esta forma, se podría romper con el riesgoso simplismo teórico que estaría impactando negativamente y a escala global tanto al avance teórico como a la utilidad práctica de la economía política.

Finalizando el siglo XIX, Engels y Marx (2004) enfocaron el programa del Partido Comunista en el análisis de cierta funcionalidad desequilibrada del capitalismo. Afirmaron que "cada crisis destruye regularmente no solo una masa de productos ya creados, sino, todavía más, una gran parte de las mismas fuerzas productivas" (Engels \& Marx, 2004). La tesis se vio reforzada por el neomarxismo francés, que sugirió que el aparato de Estado operaría como sujeto a las tensiones producidas por los intereses de los propietarios de los diferentes factores de producción (Poulantzas, 1980).

El que Engels y Marx (2004), en los albores del capitalismo, hubieran tenido la capacidad de observar la estructura cambiante y tensional del sistema resulta una señal estimulante de prueba sobre la hipótesis del artículo. Todo porque las fuertes tensiones del sistema en absoluto están conduciendo a identificar algo conocido como estado de igualdad. Todo lo contrario, y tal como lo prueba el artículo, la evolución del comercio internacional por sectores económicos que actúan en desequilibrio unos con otros es una evidencia de que se puede ratificar incluso en breves lapsos de tiempo.

Tomando en cuenta algunos principios de la mecánica cuántica, se podría afirmar que en los estados máximos de desequilibrio la naturaleza, lo mismo que la economía de un país, produciría drásticos cambios. Prigogine (1993) propone al respecto que:

La sociedad [...] funciona lejos del equilibrio [...] el comportamiento del individuo puede transformar el funcionamiento global de la sociedad [...] porque el régimen global se halla en un estado de inestabilidad estructural [...] más allá de un umbral determinado [...] calculable con arreglo a modelos simples.

En relación con lo anterior, encontramos soportes también en Morin (1977) y, más en detalle, en Engels y Marx (2004).

Por otra parte, actualmente se aprecia en América Latina 
que el Estado garantiza que determinadas reglas de competencia funcionen, pero no tendría cómo ni por qué garantizar resultados iguales. De modo que los planes de desarrollo, como el de la "locomotora minera" del gobierno Santos (2010), explicarían los resultados que se presentan en este artículo. Se confirma así que la minería es un sector líder del comercio internacional en Colombia en el lapso observado.

En consecuencia, los choques conceptuales entre una desusada forma de entender la economía con base en el uso de patrones clásicos deterministas, anclados como están al equilibrio como parámetro evaluador del éxito o fracaso de políticas públicas, debería ser retada por la moderna concepción cuántica del desequilibrio, que, de adoptarse, permitiría entender mejor la realidad compleja del capitalismo moderno (Congote \& Tellez, 2017).

Podría ocurrir que detrás de los enfoques clásicos sobre el equilibrio como parámetro evaluador de la economía pudiera explicarse por qué se está devaluando el papel creativo y la potencia del impacto que tienen las recomendaciones de los economistas en las políticas públicas modernas 4 . Al respecto, conviene tener en cuenta, a manera de llamado de alerta, que se hace urgente:

Establecer una sensible diferencia entre la insatisfacción intelectual profunda (que suscitan las explicaciones clásicas) y la inquietud, la nostalgia, que en algunos pueda evocar que un cosmos armonioso en el que cada cual tuviera su puesto estuviese previsto y contribuyese a la finalidad del todo [...] no es contra la ciencia (como puede) realizarse la inteligibilidad de los procesos [...] sino con la ciencia liberada por su propio desarrollo de los supuestos que posibilitaron sus primeros pasos y que, desde entonces, constituyen un obstáculo (Morin, 1977; Prigogine, 1993).

La multiforme realidad no depende de la teoría para existir. Al contrario, los teóricos estarían obligados a ver, observar y replicar la realidad en sus múltiples manifestaciones, cuando trabajen probando o falseando hipótesis. Probablemente víctimas de presiones políticas diversas, algunos neoteóricos económicos se elevan denunciando el crecimiento desigual como explicación de los males modernos, de suerte que inducen terapias erráticas (Kuper, 2019; Piketty, 2014)5.

Ahora, convendría hacer énfasis en que la complejidad

\footnotetext{
${ }^{4}$ Piketty (2014) descalifica como "infantil" que la "disciplina económica aún no haya abandonado su pasión por las matemáticas". A manera de crítica, el artículo intenta probar que puede ser cierto lo contrario, de modo que resulte no tanto infantil sino síntoma de cierta pereza mental pensar que la dinámica económica opere por fuera de las
}

desequilibrada tiende a imponerse sobre el idealismo igualitarista. Basta con observar los datos del atraso empresarial (Álvarez et al., 2018) que algunos se atreven a contraponer como "alternativa real" frente a la creciente dinámica sectorial minera. No faltaba más que un modelo fracasado sustituyera a uno exitoso. Superada la comodidad de esos diagnósticos y terapias igualitaristas, convendría dejar de utilizar los supuestos clásicos de equilibrio, estabilidad o igualdad de resultados, para formular políticas públicas, por algunos cuánticos que, como lo prueba el artículo, permitan explicar mejor la incertidumbre, la impredecibilidad y el desarrollo desequilibrado propios de la realidad moderna.

Al final, resultaría absurdo sugerir que el mundo en los siglos pasados fue igualitarista pero que ahora se ha convertido en impredecible. Los datos disponibles sugieren que el universo siempre ha sido impredecible, solo que antes no se tenían las herramientas para entenderlo (Hawking, 2018; Hawking \& Mlodinow, 2010).

\section{Hipótesis}

En el lapso 2008-2017 el sector minero colombiano ha impulsado la dinámica económica internacional hasta el punto de que, al menos en el corto plazo, ningún otro sector estaría en capacidad de emularla.

\section{Dinámica de las exportaciones colombianas}

\section{Promedios exportados}

Durante el periodo 2008-2017, las exportaciones colombianas registraron un promedio oscilante alrededor de los 46.000 millones USD anuales (ver Gráfico 1).

Bajo este espectro, durante el lapso 2008-2017:

- El sector minero generó aproximadamente el $51 \%$ del promedio total de divisas (algo más de 1 USD por cada 2 USD exportados).

- Por su parte, el sector industrial generó el $43 \%$ del promedio total.

- Finalmente, los sectores agropecuario y demás sectores ocuparon la última escala de participación, con el $5 \%$ y el $1 \%$, respectivamente.

Exportaciones por grandes sectores CIIU durante la década (2008-2017).

ciencias básicas, la física, por sobre todas.

${ }^{5}$ Piketty publicó recientemente un libro en inglés titulado Capitalism and Ideology en el que profundiza en sus especulaciones sobre la importancia de procurar el "crecimiento igualitario" (Kuper, 2019). 
Ahora, tal como se puede observar en el Gráfico 2, los fenómenos anteriores aparecen consistentes en la década, solo con excepción de los años 2008, 2009 y
2016, cuando el sector industrial había superado al sector minero en cuanto a exportaciones se refiere.

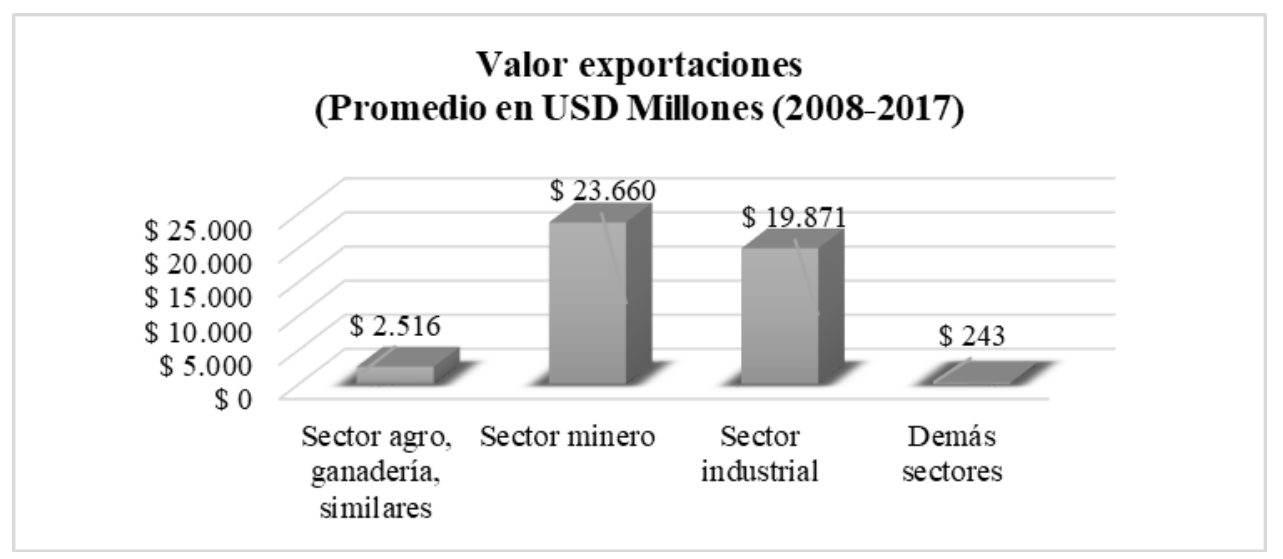

Gráfico 1. Valor exportado según grandes sectores CIIU (Promedio simple (2008-2017)). Fuente: Autor a partir de estadisticas del DANE (2019b).

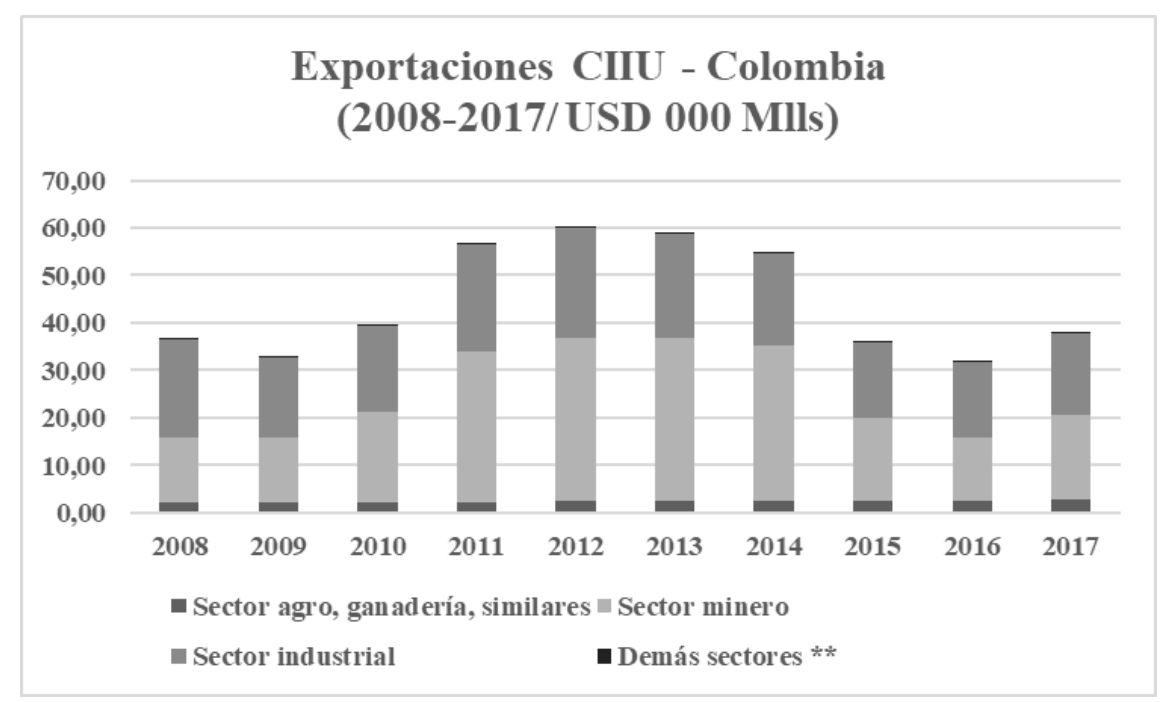

Gráfico 2. Exportaciones colombianas por sectores CIIU (2008-2017). Fuente: Autor a partir de información del DANE (2019b).

En paralelo, el comportamiento de los sectores agropecuario y demás sectores, propuestos ambos como soluciones a una no demostrada enfermedad minera, no parecían serlo, al menos en el corto plazo. Esto, dado que sus capacidades generadoras de divisas, según lo observado en la década analizada, parecían incapaces de acortar la brecha.

Por una parte, porque mientras las exportaciones mineras crecieron al $2,7 \%$ anual en la década, las agropecuarias lo hicieron al 2,6\% anual (pasando de 2,1 miles de millones

6 Las exportaciones agropecuarias de 2014 ascendieron aproximadamente a 2.500 millones USD, de modo que estos productos generaron apenas el $2 \%$ de esas divisas. Por su parte, 2018 tuvo exportaciones sectoriales de aproximadamente 1.315 millones USD. Los 128 millones USD exportados habrían generado apenas el 9,7\% de las divisas sectoriales.
USD a 2,7 miles de millones USD), datos que anunciarían aumentar la brecha, no disminuirla.

Algunos datos publicados por la Asociación Nacional de Instituciones Financieras (ANIF) permitirían develar la realidad estadística del fenómeno (Clavijo, 2019a). En efecto, afirma la fuente que:

Escuchamos menciones a los 'planes piloto' de productos como la uchuva, la gulupa y el aguacate. Sin embargo, la suma de exportaciones de estos productos fue de 51.000 millones USD en 2014 y se elevó a 128.000 millones USD en 2018 [... $]^{6}$. Se continúa hablando que las exportaciones de aguacate Hass colombiano [...] aun así, tan solo llegamos a exportar 63.000 millones de aguacate Hass durante 2018 (Clavijo, 2019a). 
De otra parte, demás sectores habrían decrecido a menos de $12 \%$ anual (de 337.000 millones USD a 88.000 millones USD). Dado que buena parte de estos son los acogidos bajo el espectro de la "economía naranja", está probado en la década analizada el largo trecho que todavía deben recorrer estos rubros para, al menos, alcanzar las tasas históricas de crecimiento exportador del sector minero.

\section{Dinámica de las importaciones colombianas}

\section{Promedios importados}

Esta dinámica contrasta con la exportadora. En primer lugar, durante el lapso 2008-2017 las importaciones colombianas oscilaron en promedio alrededor de los 74,5 mil millones USD, de modo que resultaron 1,6 veces mayores que las exportaciones. Este fenómeno ayudaría a explicar la existencia de cierto estado deficitario crónico en la balanza comercial colombiana $y$, asimismo, en la balanza de pagos ${ }^{7}$.

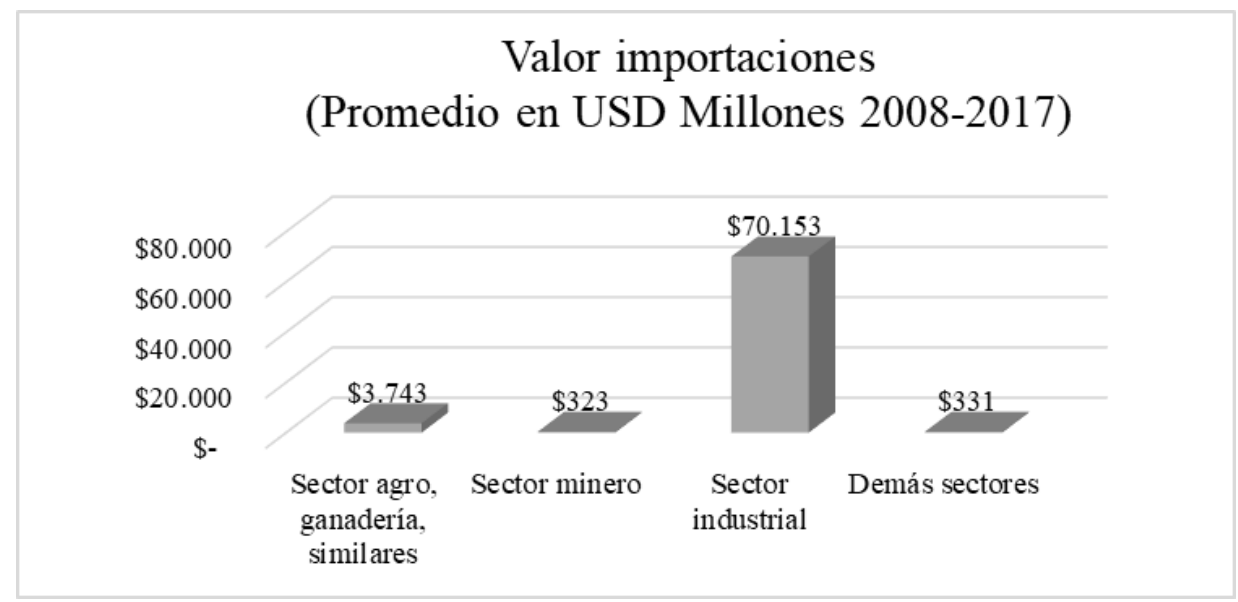

Gráfico 3: Valor importado según grandes sectores CIIU (Promedio simple ( 2008-2017). Fuente: Autor a parttir de estadisticas del DANE (2019C).

El Gráfico 3 permite analizar lo siguiente:

- Al contrastar con la dinámica exportadora, se observa que el sector minero tuvo una participación aproximada del $0,4 \%$ de las divisas totales de importación $(0,4$ centavos USD de cada 1 USD importado). Por su parte, el sector industrial mostró ser el mayor importador, demandando 94 USD de cada 100 USD importados.

- En paralelo, el sector agropecuario y demás sectores desempeñan también una función menor semejante a la exportadora, con una participación del $5,0 \%$ y el $0,4 \%$ de las divisas totales, respectivamente ${ }^{8}$.

\section{Importaciones por grandes sectores CIIU durante la década} 2008-2017

En el Gráfico 4 se pueden observar las importaciones por grandes sectores económicos en el periodo de estudio 2008-2017.

\section{La realidad minera del comercio exterior de Colombia}

\footnotetext{
7 Se podría estimar, comparando los promedios, la existencia de un déficit agregado de balanza comercial de aproximadamente 21.000 millones USD durante la década.

${ }^{8}$ Se anota que, independientemente de su mínima magnitud, los
}

Los datos observados hasta aquí permiten emitir algunas conclusiones preliminares sobre el papel impulsor de la minería en el comercio internacional colombiano; y en paralelo, contribuyen a desnudar cierto papel recesivo a cargo de los otros sectores económicos.

En primer lugar, conviene precisar la magnitud del déficit crónico de la balanza comercial durante la década comprendida entre 2008-2017 (con excepción de 2011) (ver Tabla 1 y Gráfico 5).

En segundo lugar, las dinámicas exportadoras e importadoras colombianas muestran en el Tabla 2 otros datos relevantes.

De aquí se infiere, entre otros datos, que:

- Comparando la magnitud de exportaciones frente a las importaciones durante la década, el sector minero generó por exportaciones 73 veces más divisas que las que consumió por importaciones, lo que lo convierte en un sector generador neto de divisas.

"demás sectores" también serían generadores netos de divisas, porque mientras generaron el $1 \%$ del total exportado, insumieron el $0,4 \%$ del total importado; fenómeno que augura impactos positivos. 
- Esta capacidad generadora neta superaría de manera superlativa los papeles consumidores netos de divisas que muestran, en diversas proporciones, los sectores industrial, agropecuario y demás sectores.

- En efecto, el sector industrial, por cada divisa que genera exportando, solo estaría recuperando 0,28 centavos USD de las que consume importando.

- Los sectores agropecuario y demás sectores se muestran menos gravosos que el industrial, generando 0,67 y 0,73 centavos USD de divisa por cada una de las que insumen importando.

- El sector agropecuario y demás sectores se mantienen lejos de la importancia del sector minero. Por defecto, podría inferirse que, durante la década observada, el sector industrial habría sido el mayor contribuyente al déficit crónico de la balanza comercial de Colombia (ver Tablas 1 y 2$)^{9}$.

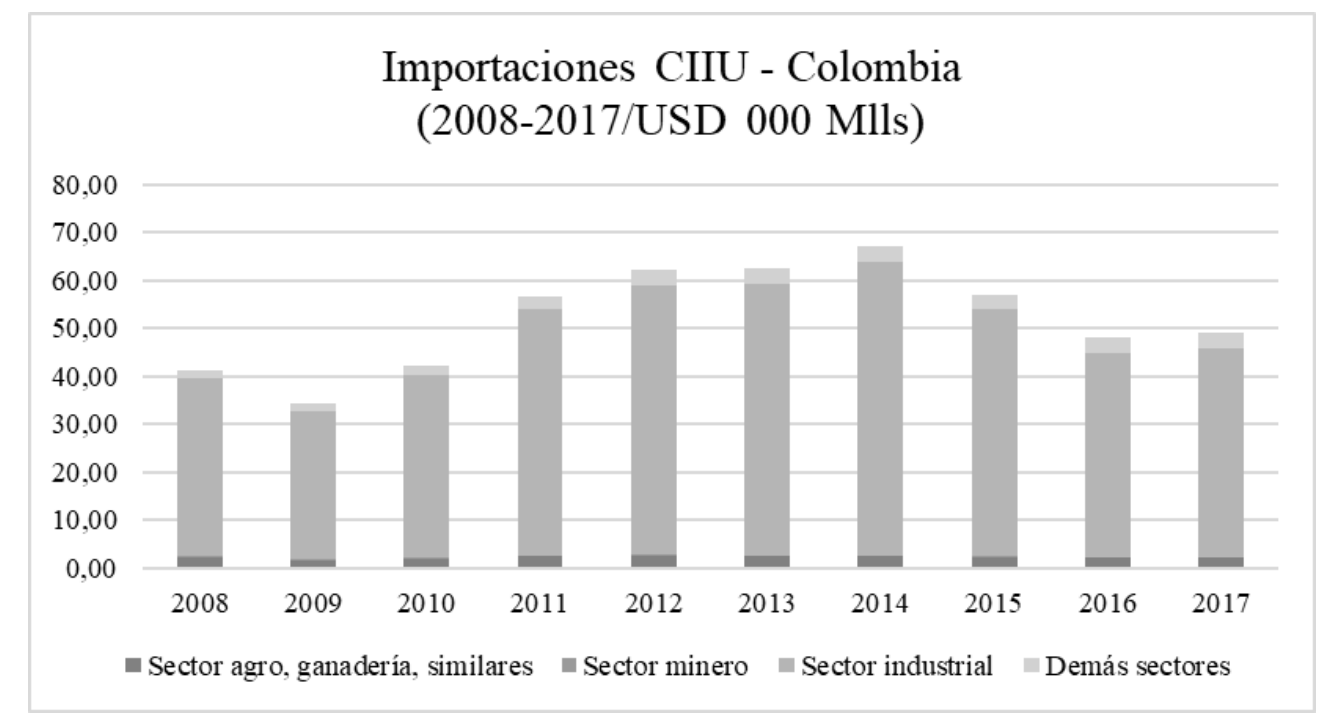

Gráfico 4: Importaciones colombianas según CIIU (2008-2017). Fuente: Autor a partir de datos del DANE (2019c).

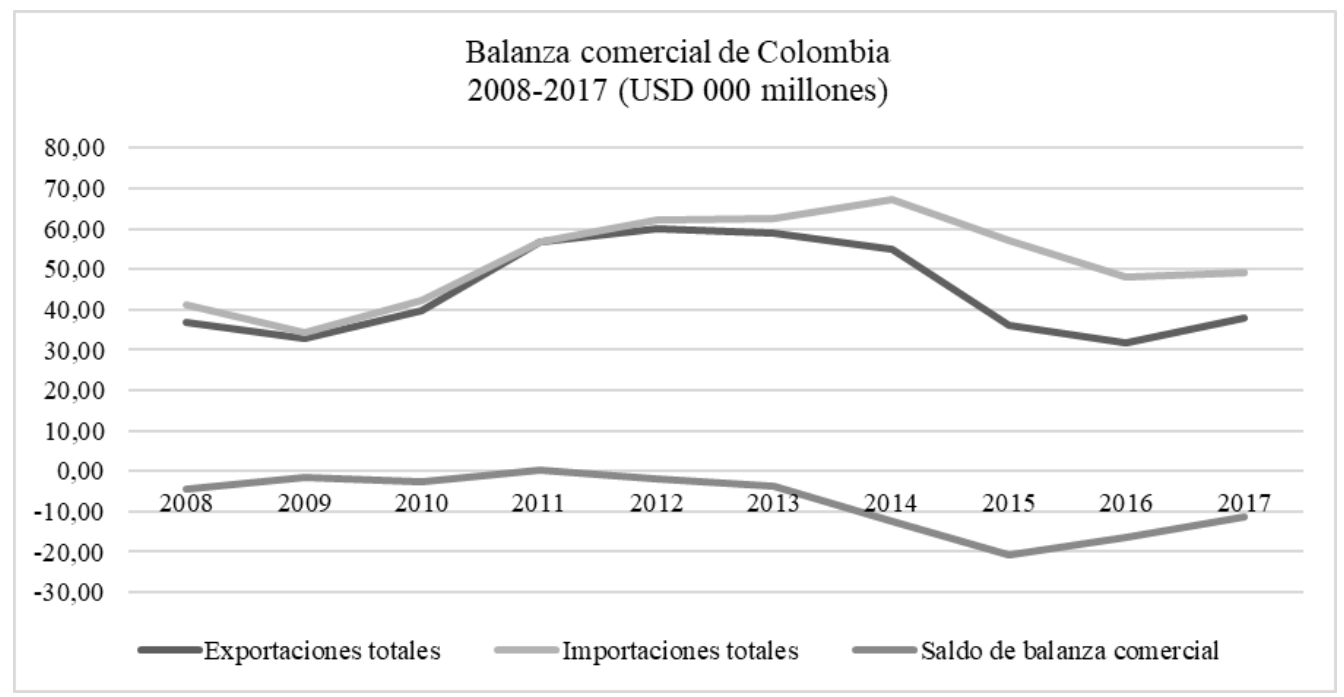

Gráfico 5. Expresión gráfica del déficit crónico de balanza en Colombia. Fuente: Autor a partir de información de la Tabla 1.

${ }^{9}$ En este artículo el análisis no llega a cubrir los estados de cuenta corriente ni balanza de pagos, por hallarse fuera de sus objetivos. 
Tabla 1

Estimación de los saldos de la balanza comercial en Colombia durante 2008-2017 (millones de dólares [USD])

\begin{tabular}{lccccccccccc}
\hline \multicolumn{1}{c}{ Ítem } & $\mathbf{2 0 0 8}$ & $\mathbf{2 0 0 9}$ & $\mathbf{2 0 1 0}$ & $\mathbf{2 0 1 1}$ & $\mathbf{2 0 1 2}$ & $\mathbf{2 0 1 3}$ & $\mathbf{2 0 1 4}$ & $\mathbf{2 0 1 5}$ & $\mathbf{2 0 1 6}$ & $\mathbf{2 0 1 7}$ & Década \\
\hline Exportaciones totales & 36,79 & 32,85 & 39,71 & 56,91 & 60,13 & 58,83 & 54,86 & 36,02 & 31,77 & 37,88 & 445,74 \\
Importaciones totales & 41,34 & 34,46 & 42,37 & 56,70 & 62,14 & 62,40 & 67,23 & 56,95 & 48,02 & 49,19 & 520,81 \\
Saldo de balanza comercial & $-4,55$ & $-1,61$ & $-2,65$ & 0,21 & $-2,02$ & $-3,57$ & $-12,37$ & $-20,93$ & $-16,26$ & $-11,31$ & $-75,07$ \\
\hline
\end{tabular}

Fuente: Autor a partir de estadística DANE (2019a).

Tabla 2

Comparación de las dinámicas exportadora e importadora de Colombia (2008-2017)

\begin{tabular}{lccccc}
\hline \multicolumn{5}{c}{ Dinámica expo-importadora colombiana por sectores CIIU (2008-2017) (millones de dólares [USD]) } \\
\hline \multirow{2}{*}{ CIIU } & \multicolumn{2}{c}{ Exportaciones(x) } & \multicolumn{2}{c}{ Importaciones (M) } & X/M \\
& Suma 2008-2017 & Participación \% & Suma 2008-1017 & Participación \% & $\mathbf{2 0 0 8 - 2 0 1 7}$ \\
\hline Sector agro, ganadería, similares & 25159,8 & $5,44 \%$ & 37434,8 & $5,02 \%$ & 0,6721 \\
Sector minero & 236596,7 & $51,11 \%$ & 3227,6 & $0,43 \%$ & 73,3036 \\
Sector industrial & 198706,1 & $42,93 \%$ & 701534,7 & $94,10 \%$ & 0,2832 \\
Demás sectores & 2432,8 & $0,53 \%$ & 3312,6 & $0,44 \%$ & 0,7344 \\
\hline
\end{tabular}

Fuente: Autor a partir de la Tabla 1 y datos fuente de los Gráficos 1 y 3.

\section{Conclusiones y recomendaciones}

Los resultados permiten comprobar la hipótesis de que, al menos en el corto plazo, la dinámica del comercio internacional colombiano no muestra algún otro sector capaz de competir con el minero en materia de importancia.

Por otra parte, existe la probabilidad de que la degradación de la importancia minera en el comercio internacional colombiano frente a los otros sectores productivos esté inspirada en los preceptos del "crecimiento igualitario", que especulan sobre la presunta necesidad de que "todos los sectores económicos crezcan en condiciones de igualdad" (Piketty, 2014).

Esta investigación no se suma al coro de quienes demeritan per se los impactos que pueden tener el déficit de balanza sobre la economía. Asociado ese síndrome "igualitarista" al uso de herramientas clásicas para explicar la compleja modernidad capitalista, en el caso de Colombia es posible probar, por ejemplo, que las posiciones arancelarias importadas por el sector industrial obedecen preferentemente a materias primas y bienes de capital, lo que ha constituido por décadas un fenómeno de impactos macroeconómicos positivos.

Entre tanto, Colombia está descuidando el hecho de diagnosticar y resolver su probada incapacidad industrial para recuperar, exportando, las divisas que el sector consume importando. Por esto, el problema no se le puede atribuir a dificultades propias del comercio internacional, al denunciarlo deficitario o "desigual". Por el contrario, es preciso atribuirlo a contradicciones relacionadas, entre otros aspectos, con el deficiente empleo de factores y la baja productividad sectorial.

En efecto, las cifras negativas del comercio internacional de la industria estarían asociadas a cierta proclividad rentista de las empresas. De esta forma, la estructura del mercado, junto con incentivos perversos estatales (del tipo exenciones, subsidios generales o exenciones no auditadas hacia las zonas francas), induciría al sector industrial a conformarse con el statu quo, olvidándose de generar transformaciones tecnológicas o induciendo la investigación de mercados hacia la apertura de nuevos destinos exportadores ${ }^{10}$.

Por consiguiente, sería saludable buscar explicaciones a los impactos negativos del sector industrial sobre la balanza comercial, más bien en su probable improductividad estructural, tal como recientemente lo habría demostrado el estudio de Álvarez et al. (2018).

Resueltas las falacias de composición que se acaban de enunciar, se podría construir el camino que permita una adecuada y objetiva comprensión de los positivos impactos del sector minero en el comercio internacional colombiano.

Adicionalmente, entidades como la ANIF se han adueñado de un saludable diagnóstico del problema,

\footnotetext{
${ }^{10}$ La estructura rentista obstaculiza la innovación de las firmas y las deja postradas antes de alcanzar los mercados externos, lo que se traduce en carencia de firmas de tamaño intermedio y obstaculización del poder para exportar productos o servicios diferentes a los commodities minero-energéticos (tan típicos de la región) (Clavijo, 2019a, 2019b).
} 
relacionándolo con los denominados "Costos Colombia". Con este concepto, hacen referencia al alto impacto que tienen sobre la capacidad de competir de nuestros productos exportados (y exportables); $y$ las dificultades de la estructura logística nacional, apenas resueltas tímidamente mediante iniciativas como el impulso a las autopistas viales de generación 3 y 4 . Estos aspectos se evidencian en estudios como el de Romero (2019).

Esta investigación no tiene entre sus objetivos el de abordar la discusión del presunto impacto ambiental negativo generado por las actividades mineras. Pero sí aporta la idea de que, como se observa en Colombia, dado que resulta importante el superávit comercial del sector minero, convendría canalizar una determinada proporción de las divisas superavitarias, con el fin de facilitar que la minería pueda importar tecnología de punta no invasiva con el medioambiente ${ }^{11}$.

Finalmente, se invita a cultivar la expectativa de que análisis paralelos sobre la dinámica sectorial CIIU del comercio internacional de otros países de la región panamericana podrían contribuir a un diagnóstico macrosectorial que, entre otros objetivos, lograra avanzar hacia cierta conveniente "desatanización" regional del sector minero que, como se muestra aquí, preliminarmente no tendría sustento fáctico.

\section{Referencias bibliográficas}

Álvarez, F., Eslava, M., Sanguinetti, P., Toledo, M., Alves, G., Daude, C., \& Allub, L. (2018). RED 2018.Instituciones para la productividad: hacia un mejor entorno empresarial. Caracas: Banco de Desarrollo de América Latina - CAF. Recuperado de http://scioteca.caf.com/ handle/123456789/1343

Buitrago, F., \& Duque, I. (2013). La Economía Naranja: Una oportunidad infinita. Banco interamericano de Desarrollo. Puntoaparte Bookvertising.

Clavijo, S. (2019a, July 22). Éxito agroexportador de Chile y Perú: ¿y Colombia? La República. Recuperado de https://www.larepublica.co/analisis/sergioclavijo-500041/exito-agroexportador-de-chile-yperu-y-colombia-2887707

Clavijo, S. (2019b, July 25). Diversificación exportadora y rentas monopólicas. La República. Recuperado de https://www.larepublica.co/analisis/sergioclavijo-500041/diversificacion-exportadora-yrentas-monopolicas-2888670

Congote, B., \&Tellez, M. (2017). Cómo mejorar la enseñanza y el aprendizaje de teoría económica aplicando algunas herramientas cuánticas. Tecnogestión: Una Mirada Al Ambiente, 14(1). Recuperado de https:// revistas.udistrital.edu.co/index.php/tecges/article/

\footnotetext{
"Sobre estos asuntos, la revista Minería Pan-Americana ofrece ejemplos
} que se pueden adoptar para modificar estos impactos. view/12633

DANE. (2019a). Estadísticas por tema, comercio internacional. Recuperado de https://www.dane. gov.co/index.php/estadisticas-por-tema/comerciointernacional

DANE. (2019b). Exportaciones. Recuperado de https:// www.dane.gov.co/index.php/estadisticas-por-tema/ comercio-internacional/exportaciones

DANE. (2019c). Importaciones. Recuperado de https:// www.dane.gov.co/index.php/estadisticas-por-tema/ comercio-internacional/importaciones

Engels, F., \& Marx, K. (2004). El manifiesto comunista. (Akal S.A., Ed.) (1. a ed.). Barcelona: Critica.

Hawking, S. (2018). Breves respuestas a las grandes preguntas (Crítica). Barcelona.

Hawking, S., \& Mlodinow, L. (2010). El gran diseño. (Crítica, Ed.) (Vol. 41). Barcelona: Administración \& Desarrollo.

Kuper, S. (2019, September 27). Desigualdad: este es el momento de repartir la riqueza. Portafolio. Recuperado de https://www.portafolio.co/ economia/desigualdad-este-es-el-momento-derepartir-la-riqueza-534027

Morin, E. (1977). El método, I: la naturaleza de la naturaleza. (Cátedra, Ed.). Madrid.

Morin, E. (1982). Science Avec Conscience. (Fayard, Ed.). Paris: Canadian Political Science Association.

Morin, E. (1990). Introducción al pensamiento complejo. (Gedisa, Ed.). España.

Morin, E. (1992). El método, IV: Las ideas. (Cátedra, Ed.). Madrid.

Ortíz, K. (2019). Impacto del turismo del paisaje cultural cafetero en la denominada "Economía Naranja" (20132016). Universidad Antonio Nariño. Facultad de Economía y Ciencias Administrativas.

Piketty, T. (2014). El capital en el siglo XXI. Fondo de Cultura Económica.

Poulantzas, N. (1980). Estado, podery socialismo. (Siglo XXI, Ed.). España.

Prigogine, I. (1993). ¿Tan sólo una ilusión? (Tusquets, Ed.) (3. ${ }^{a}$ ed.). Barcelona.

Prigogine, I., \& Stengers, I. (1983). La nueva alianza. Metamorfosis de la ciencia. (Alianza, Ed.). Madrid.

Romero, W. (2019). Competitividad logística y facilitación de las exportaciones en Colombia. Universidad Antonio Nariño. Facultad de Economía y Ciencias Administrativas.

Santos, J. M. (2010). Capitulo 1. Hacia la prosperidad democrática: Visión 2010-2014. In Plan Nacional de Desarrollo 2010-2014. Departamento Nacional de Planeación. Recuperado de https://www.dnp.gov. co/Plan-Nacional-de-Desarrollo/PND-2010-2014/ Paginas/Plan-Nacional-De-2010-2014.aspx

Serway, R. A., \& Jewet., J. W. (2002). Física para ciencias $e$ ingeniería (5a Edición, Vol. 2). México: Cengage Learning. 